\title{
THE Effect of Precision Nitrogen Topdressing Decision on Winter Wheat
}

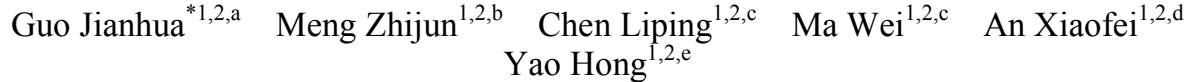 \\ ${ }^{1}$ Beijing Research Center for Intelligent Agricultural Equipment, Beijing 100097, China; \\ 2 National Research Center of Intelligent Equipment for Agriculture, Beijing 100097, China. \\ auojh@nercita.org.cn, ${ }^{b}$ mengzj@nercita.org.cn, ${ }^{\mathrm{a}}$ chenglp@nercita.org.cn, \\ dmaw@nercita.org.cn, , ${ }^{\mathrm{e}}$ anxf@nercita.org.cn, ${ }^{\mathrm{f}}$ yaoh@nercita.org.cn,
}

\begin{abstract}
Topdressing in the growth period is the key to high yield of wheat. So how to use the rapid detection technique to realize scientific and real-time topdressing for lower fertilizer application and higher use efficiency of fertilizer is critical to agricultural development. The aim of this study is to investigate the effect of fertilization as affected by different topdressing recommendations. In this study, field experiments are conducted at Xiaotangshan Precision Agriculture Demonstration Base in Beijing, using commonly-used rapid detection equipment. The experimental results are summarized as follows: Variable rate fertilization based on nitrate nitrogen level in soil and grower's uniform fertilization are basically same in fertilizing amount but the former produces higher yield of $320 \mathrm{~kg} / \mathrm{ha}$; high rate application based on low measured NDVI value in the reviving stage leads to highest fertilizer productivity at $19.3 \mathrm{~kg} / \mathrm{kg}$, with an increase of $10.4 \mathrm{~kg} / \mathrm{kg}$ compared with grower's uniform fertilization; in terms of profitability, high rate application based on low measured NDVI value in the reviving stage produces highest profit of 12,649 yuan/ha, while high rate application based on high measured SPAD value and high measured NDVI value in the reviving stage produce lowest profits of 9,358 yuan/ha and 9,775 yuan/ha respectively.
\end{abstract}

Keywords: Topdressing wheat, Precision decision-making, Topdressing recommendation

\section{Introduction}

Fertilizer is regarded as material guarantee of sustainable agricultural development and also the key to higher grain yield. It is proven by agricultural development practices that fertilization is the most rapid, efficient and important means of increasing grain yield. China has now become the largest producer and consumer of fertilize (1). The amount of fertilizer applied in China takes up about $1 / 3$ of total amount of global fertilization. Growers tend to spread fertilizer out evenly on the soil surface, which means the rate of fertilizer application is same in one application area or with one grower regardless of varied soil nutrients. As a result, too many fertilizers are applied on high-nutrient soils, leading to low use efficiency of fertilizer. 
The average application rate of fertilizer was developed two times the upper limit of the safe use of chemical fertilizers and the average utilization rate of is about $40 \%$. China's arable land accounted for $7 \%$ of the world's arable land, but the use of $35 \%$ of the fertilizer over the world.(2). Considerable loss of fertilizer has

triggered various environmental problems. For example, in some areas characterized by highly intensive agriculture in Beijing, the improper application of fertilizer $\mathrm{N}$ has caused excessive nitrate contained in underground water, the content of which even reaches $100 \%$ in some areas.

With the development of soil test-based fertilizer recommendation and balanced fertilization technologies, fertilizer's rate of contribution to soil increases gradually and fertilizers applied elevate the grain yield. The traditional testing technique used to be widely applied because of its precision in the test procedures and results. However, due to high workload, time-consuming feature and complicated operation, coupled by limitation in environment, equipment and technology, such testing technique is unlikely to meet the requirements of agricultural modernization. As modern science and technology continue to develop, various sensor-based non-destructive rapid testing equipment and technologies are developed, such as the SPAD Chlorophyll Meter made in Japan. Chlorophyll meter is a tool used to rapidly measure the level of chlorophyll contained in crop leaves, which is now gradually recognized and popularized by experts. At present, it has been applied in $\mathrm{N}$ nutrition determination for rice, corn, wheat and other crops ${ }^{[3,4,5]}$.

In this study, effective nitrogen level in soils $(0-20 \mathrm{~cm} \& 20-40 \mathrm{~cm})$ is measured along with SPAD value, NDVI value and nitrate content in leaves in the reviving stage for purpose of precision fertilization. Then the decision-making on precision topdressing and the effect of precision fertilization are examined and evaluated with the intent to improve the use efficiency of fertilizer $\mathrm{N}$, maximize ecological economic benefit, and provide guidance for agricultural production.2 The structure of soil parameter distribution map system

\section{Experimental Material and Method}

\subsection{Experiment design}

The experiments were conducted during Mar. 2013 and Jun. 2013 on the fields in Xiaotangshan Precision Agriculture Demonstration Base in Changping District, Beijing. The tested wheat is Jingdong 12, which was sown mechanically on Oct. 3, 2012 at a rate of $13 \mathrm{~kg} / \mathrm{mu}$ by applying base fertilizer DAP at rate of $15 \mathrm{~kg} / \mathrm{mu}$. Sprinkling irrigation is applied.

After entering the reviving stage, the trial zone is delineated through DGPS locating and boundary defining. Then samples are extracted in zigzagging form from the soils at depths of $0-20 \mathrm{~cm}$ and $20-40 \mathrm{~cm}$ in subzones of the trail zone. Following that, the contents of nitrate nitrogen and water in the soil samples are measured, then SPAD value, NDVI value and nitrate content in leaves. Finally, the amount of fertilizer $\mathrm{N}$ to 
be top dressed is figured out. Meanwhile, field trials of different rates of fertilizer N application are carried out.

Table 1 Topdressing Recommendations

\begin{tabular}{|c|c|c|}
\hline \multirow{4}{*}{$\begin{array}{c}\text { Test Item } \\
\text { Litrate in }\end{array}$} & Index & $\begin{array}{r}\text { Recommen } \\
\text { ded Amount }\end{array}$ \\
\hline & $>1400$ & 0 \\
\cline { 2 - 3 } & $1000-$ & 8 \\
\cline { 2 - 3 } & $800-1000$ & 10 \\
\cline { 2 - 3 } & $600-800$ & 13 \\
\hline \multirow{3}{*}{ SPAD } & $<600$ & 15 \\
\hline \multirow{3}{*}{ GREENSE } & $<47$ & 15 \\
\cline { 2 - 3 } EK & $47-50$ & 10 \\
\cline { 2 - 3 } & $>50$ & 8 \\
\cline { 2 - 3 } & $0.45-0.47$ & 18 \\
\cline { 2 - 3 } & $0.47-0.5$ & 12 \\
\hline
\end{tabular}

\subsection{Measurement of NDVI value}

NDVI data is collected using hand-held GreenSeeker NDVI meter produced by U.S. Ntech. The NDVI meter works based on an active remote sensing system, of which the red band length is $671 \pm 6 \mathrm{~nm}$, NIR band length $780 \pm 6 \mathrm{~nm}$, and spectrum width $0.6 \mathrm{~m}$. The test is conducted in a sunny forenoon in the growth period of wheat. During the test, the top end of remote sensor must be adjusted to be level with the ground and in parallel to wheat canopy at the same height, with a vertical height of $80-120 \mathrm{~cm}$. The typical NDVI value is obtained by averaging the NDVI values of all subzones.

\subsection{Measurement of SPAD value}

Leaf SPAD value is measured by SPAD-502 Chlorophyll Meter. The test is carried out on 20 uniformly sized wheat plants randomly selected from the subzones in a sunny forenoon on 9:00 a.m.-12:00 a.m. The SPAD value is obtained by averaging the measured values of mid-part leaf newly generated on the stem.

\subsection{Measurement of leaf nitrate content}

The instrument used for the test is a German-made nitrate reflectometer. And the test procedures are shown as follows: take a basal part of the stem, and cut into small 
pieces; use juice squeezer to get the juice out; dilute the juice by a factor of about 1020 ; inset the test strip to the liquid to be analyzed; take out the test strip and insert into the reflectometer for matching; and read out the nitrate content $(\mathrm{mg} / \mathrm{L})$ directly.

\section{Results and Analysis}

After the experiments, the growth dynamics and yield of wheat in critical growth stages are analyzed.

\subsection{Dynamic changes of NDVI value in different growth stages}

The experiments show that wheat's $\mathrm{N}$ nutrition can be expressed by NDVI value. In the erecting stage, leaves are small, so NDVI value is low; then NDVI value increases at a high rate as wheat grows at a high rate as wheat grows gradually, peaking after entering the booting stage and finally remaining stable thereafter. During the entire experimental period, different fertilizer treatments are consistent with growth changes. NDVI is a vegetation index that can reflect growth trend of crops.

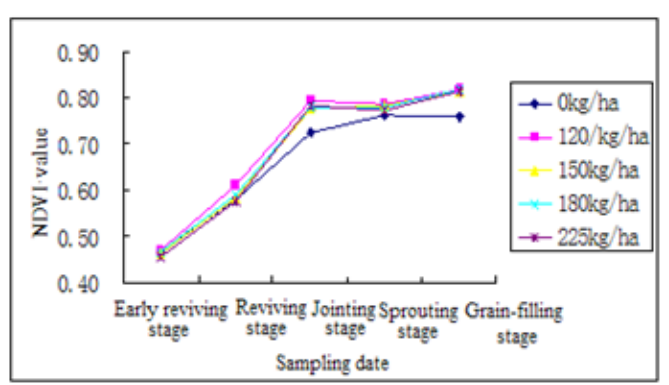

Fig.1 NDVI Value Changes Affected by Different Fertilizing Amounts

\subsection{Correlation of NDVI value with different $\mathbf{N}$ application levels}

The correlation of NDVI values obtained by GreenSeeker NDVI meter with different $\mathrm{N}$ application levels are analyzed, the result of which suggests that NDVI value is an implication of wheat's $\mathrm{N}$ level. It is a useful tool for $\mathrm{N}$ nutrition diagnosis. Therefore, by measuring NDVI value, growers can figure out the growth dynamics of wheat. Then, growers can determine the rate of topdressing application based on the growth dynamics and target yield.

In consideration of differences in wheat species, it is necessary to build a separate control field for determining an appropriate rate of topdressing application in practical production. 


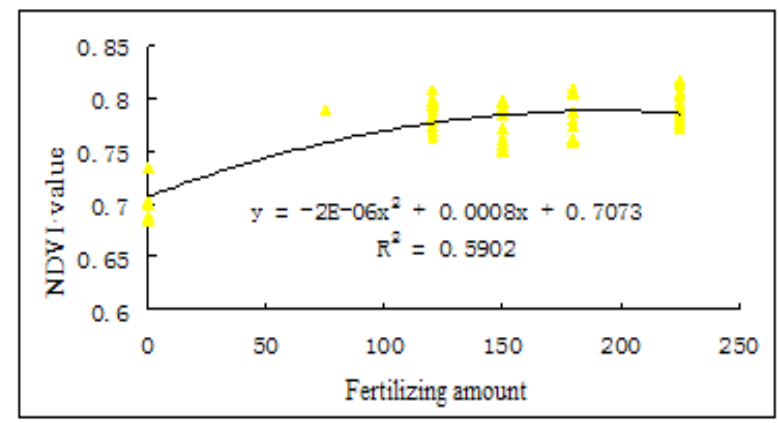

Fig.2 NDVI Value Changes Affected by Different Fertilizer Treatments

\subsection{Dynamic changes of SPAD value in different growth stages}

As can be seen from Fig. 3, during the entire experimental period, SPAD value varies with growth stages, bottoming out in the reviving stage while peaking in the heading stage. Then SPAD value declines gradually and tends to stabilize in the grain-filling stage. Such a change trend is consistent with the change of $\mathrm{N}$ nutrition [8]. Leaf $\mathrm{N}$ is mostly stored in chloroplast, so $\mathrm{N}$ level in leaf is positively correlated with chloroplast content. Chloroplast content and $\mathrm{N}$ level increase as a result of fertilization, so is SPAD value. After flowering, the plant starts to age, resulting in a decline in chloroplast and $\mathrm{N}$ levels and also SPAD value.

During the sprouting stage, SPAD value is correlated with fertilizing amount, which is especially remarkable in the grain-filling stage.

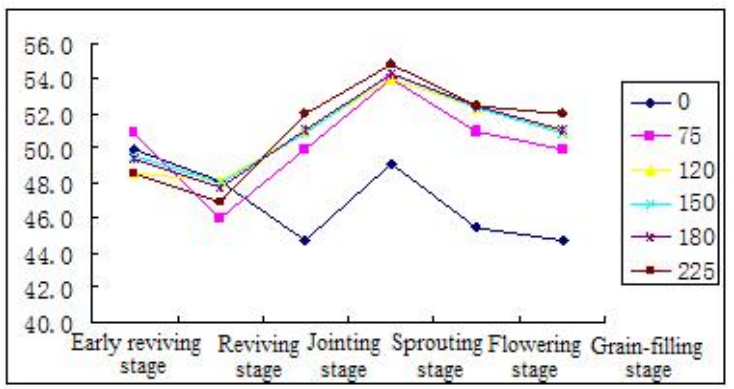

Fig.3 Measured SPAD Value in Different Growth Stages

\subsection{Correlation of SPAD value with different $\mathbf{N}$ application levels}

SPAD value is highly correlated with $\mathrm{N}$ application level. The correlation coefficients detected on Apr. 22 and May 22 are $\mathrm{R} 2=0.6262^{* *}$ and $\mathrm{R} 2=0.6774 * *$ respectively. Leaf $\mathrm{N}$ level is positively correlated with chlorophyll level while crop yield is positively correlated with leaf $\mathrm{N}$ and chlorophyll levels in specific growth stages. 
After topdressing, it takes some time for wheat to uptake the fertilizer N. So wheat is more responsive to nitrogen and SPAD value is more correlated with the rate of topdressing application in the flowing stage.

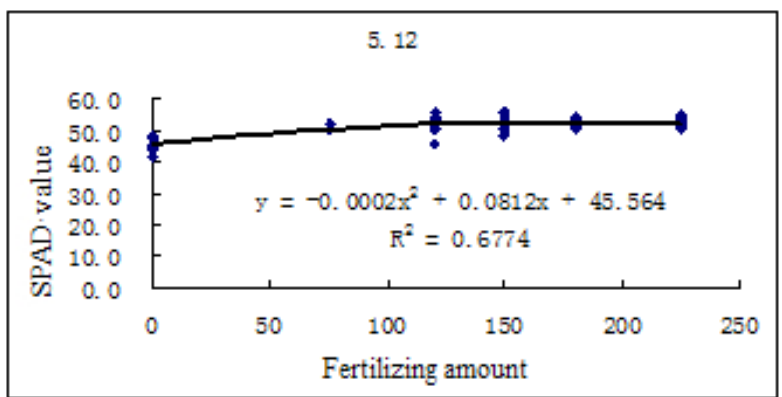

Fig.4 Correlation of SPAD Values with Different Fertilizing Amounts in Flowering Stage

\subsection{Correlation of nitrate level with $\mathrm{N}$ application level}

Wheat nitrate level is correlated with fertilizing amount, of which the correlation coefficient is $\mathrm{R} 2=0.7333$. Nitrate level varies with $\mathrm{N}$ application level and increases as more fertilizers $\mathrm{N}$ are applied. As an effective nitrogen form of plants, nitrate is a direct reflection of $\mathrm{N}$ nutrition. Nitrate level depends greatly on fertilizing amount. The higher the rate of application, the higher the nitrate level.

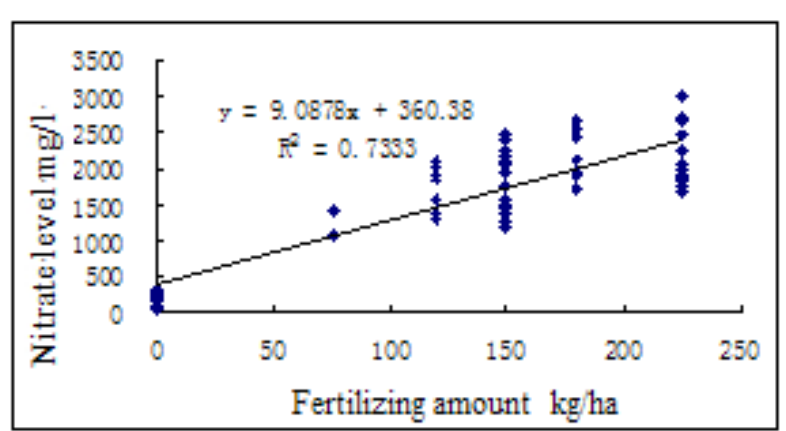

Fig.5 Correlation of Fertilizing Amount with Wheat Nitrate Level

\subsection{Correlation of chlorophyll level with fertilizing amount}

Chlorophyll is vital for photosynthesis, so the amount of photosynthate depends on chlorophyll level. To the extent that is appropriate, higher fertilizing amount produces higher chlorophyll level and more efficient photosynthesis.

During the jointing stage, nitrate level is correlated with yield. The higher the nitrate nitrogen level, the higher the yield. 


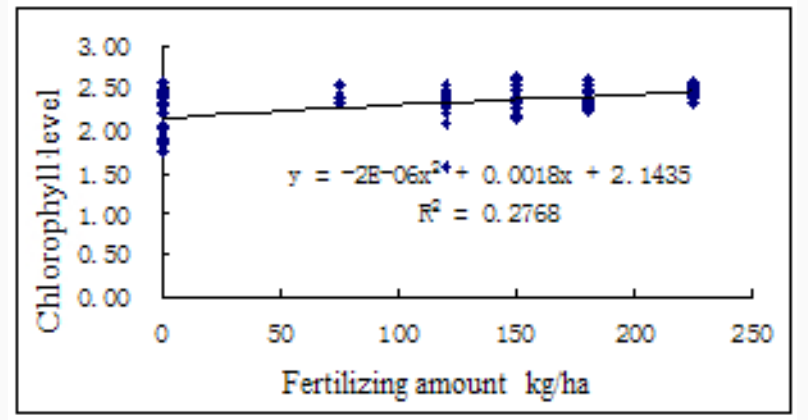

Fig. 6 Chlorophyll Levels Affected by Fertilizing Amount

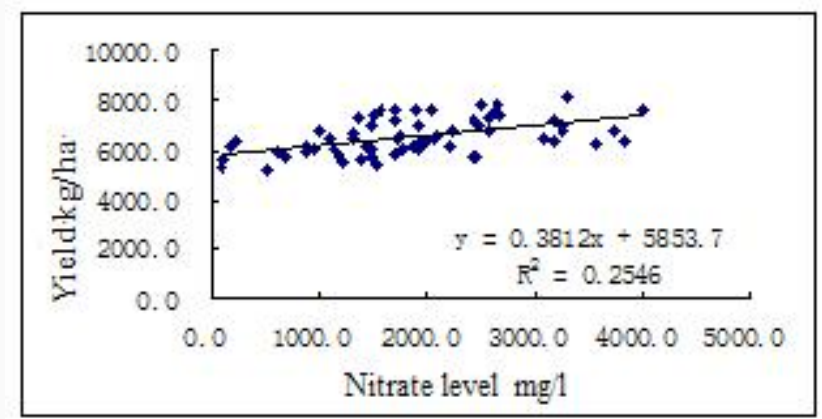

Fig. 7 Correlation of Nitrate Level with Yield in Jointing Stage

\subsection{Effects of different topdressing recommendations}

In Different topdressing recommendations derived during the reviving stage are put into practice in the field. The trial zone is divided into several $25 \mathrm{~m} 2$ subzones, in which fertilizers are applied artificially immediately followed by watering.

Table 2 Topdressing Treatment Summary

\begin{tabular}{|c|c|c|}
\hline Treatment & Code & $\begin{array}{l}\text { Subzone } \\
\text { Qty. }\end{array}$ \\
\hline ck & Control & 9 \\
\hline Unit & Local grower's uniform fertilization & 9 \\
\hline VTN & $\begin{array}{l}\text { Variable rate fertilization based on nitrate nitrogen level } \\
\text { in soil }\end{array}$ & 18 \\
\hline VS10 & $\begin{array}{l}\text { Low rate application based on high measured SPAD } \\
\text { value in the reviving stage }\end{array}$ & 18 \\
\hline V10 & $\begin{array}{l}\text { Low rate application based on high measured NDVI } \\
\text { value in the reviving stage }\end{array}$ & 18 \\
\hline
\end{tabular}


As shown in Table 3, grain yield varies with topdressing recommendations. Treatments VPN and UNT are basically same in fertilizing amount but the former produces higher yield of $320 \mathrm{~kg} / \mathrm{ha}$. As suggested by the yield-increasing effects, the fertilizer productivity varies with topdressing recommendations; the treatment V10 leads to highest fertilizer productivity at $19.3 \mathrm{~kg} / \mathrm{kg}$, with an increase of $10.4 \mathrm{~kg} / \mathrm{kg}$ compared with the treatment UNT; the treatment VS10 results in lowest fertilizer productivity at $4.8 \mathrm{~kg} / \mathrm{kg}$ (based on high measured SPAD value) and $5.9 \mathrm{~kg} / \mathrm{kg}$ (based on high measured NDVI value) respectively.

Table 3 Yields under Different Topdressing Recommendations

\begin{tabular}{|c|c|c|c|c|c|}
\hline Code & $\begin{array}{l}\text { Applica } \\
\text { tion Rate }\end{array}$ & $\mathrm{Kg} / \mathrm{ha}$ & $\begin{array}{c}\text { Yield } \\
\text { Increase }(\%) \\
\text { Compared } \\
\text { with Control }\end{array}$ & $\begin{array}{c}\text { Yield } \\
\text { Increase (\%) } \\
\text { Compared } \\
\text { with } \\
\text { Grower's } \\
\text { Uniform } \\
\text { Fertilization }\end{array}$ & $\begin{array}{r}\text { Yield } \\
\text { Increase }\end{array}$ \\
\hline CK & 0 & 4796.5 & & & \\
\hline UNI & 150 & 6129.7 & 27.8 & & 8.9 \\
\hline VT & 159 & 6588.4 & 37.36 & 7.48 & 11.3 \\
\hline $\begin{array}{l}\text { VS } \\
10\end{array}$ & 165 & 6593.4 & 37.46 & 7.56 & 10.9 \\
\hline $\begin{array}{l}\text { V1 } \\
0\end{array}$ & 132 & 7346 & 53.15 & 19.84 & 19.3 \\
\hline $\begin{array}{l}\text { VP } \\
\mathrm{N}\end{array}$ & 153 & 6449.7 & 34.47 & 5.22 & 10.8 \\
\hline
\end{tabular}

As indicated in Table 4, the treatment V10 produces a profit of 12,649 yuan/ha, with an increase of 2,268 yuan/ha compared with the control (10,381 yuan/ha); the treatments VTN and VS10 both produce lower profits compared with the treatment UNIT.

The treatment VS10 produces lowest profit of 9,358 yuan/ha (based on high measured SPAD value) and 9,775 yuan/ha (based on high measured NDVI value) respectively.

Table 4 Analysis on Profitability of Different Topdressing Recommendations 


\begin{tabular}{cccccc}
\hline Code & $\begin{array}{c}\text { Application } \\
\text { Rate } \\
\mathrm{kg} / \mathrm{ha}\end{array}$ & $\begin{array}{c}\text { Average } \\
\text { Yield Per Unit } \\
\mathrm{kg} / \mathrm{ha}\end{array}$ & $\begin{array}{c}\text { Fertili } \\
\text { zer Input } \\
\text { yuan/h } \\
\mathrm{a}\end{array}$ & $\begin{array}{c}\text { Grain Output } \\
\text { Value } \\
\text { yuan/ha }\end{array}$ & Profit \\
yuan/ha
\end{tabular}

As can be seen from Table 5, the variable coefficient of yield decreases after the treatment VTN. The variable coefficient of the control is highest (20.75\%), followed by the Treatment UNIT $(18.59 \%)$; the variable coefficient of the treatment VTN is only $4.47-14.17 \%$.

Table 5 Yield Variance under Different Topdressing Recommendations

\begin{tabular}{cccc}
\hline Code & Average Yield (kg/ha) & $\begin{array}{c}\text { Standard } \\
\text { Deviation }\end{array}$ & $\begin{array}{c}\text { Yield Variance (\%) under Different } \\
\text { Topdressing Recommendations }\end{array}$ \\
\hline CK & 4796.5 & 995.41 & 20.75 \\
UNI & 6129.7 & 1139.86 & 18.59 \\
VT & 6588.4 & 395.2 & 5.96 \\
VS10 & 6593.4 & 825.19 & 12.5 \\
V10 & 7346 & 328.38 & 4.47 \\
VPN & 6449.7 & 917.1 & 14.17 \\
\hline
\end{tabular}

\section{Result and Conclusion}

Topdressing is one of critical farming practices to realize high yield of wheat. Scientific topdressing can not only elevate crop yield but also cut down fertilizer input. Grain yield depends partly on topdressing recommendations. Variable rate fertilization based on nitrate nitrogen level in soil and grower's uniform fertilization are basically same in fertilizing amount but the former produces higher yield of 320 $\mathrm{kg} / \mathrm{ha}$. As suggested by the yield-increasing effects, the fertilizer productivity varies with topdressing recommendations; high rate application based on low measured NDVI value in the reviving stage leads to highest fertilizer productivity at $19.3 \mathrm{~kg} / \mathrm{kg}$, with an increase of $10.4 \mathrm{~kg} / \mathrm{kg}$ compared with grower's uniform fertilization; high 
rate application based on high measured SPAD value and high measured NDVI value in the reviving stage result in lowest fertilizer productivities at $4.8 \mathrm{~kg} / \mathrm{kg}$ and $5.9 \mathrm{~kg}$ / $\mathrm{kg}$ respectively. In terms of profitability, high rate application based on low measured NDVI value in the reviving stage produces a profit of 12,649 yuan/ha, and high rate application based on high measured SPAD value and high measured NDVI value in the reviving stage produce lowest profits of 9,358 yuan/ha and 9,775 yuan/ha respectively.

\section{Acknowledgment}

This study was supported by Chinese National High Science and Technology Research Project “863” No 2012AA101901 and Ministry of Agriculture nonprofit sector special Project No 201303103.

\section{References}

1. Jin J Y, Li J K, Li S T. Fertilizer and food safety [J]. J. of Plant Nutrition and Fertilizer, 2006, $12(5) 601-609$

2. Yan $\mathrm{X}$, Jin $\mathrm{J} Y$, He $\mathrm{P}$ et al. Recent advances in technology of increasing fertilizer use efficiency [J]. Scientia Agricultura Sinica, 2008, 41 (2) 450-459

3. Chapman S C, Barreto H J. Using a chlorophyl meter to estimate specific leaf nitrogen of tropical maize during vegetative growth $[\mathrm{J}]$. Agron. J., 1997, 89I: 557-562.

4. Wu L H, Tao Q N. Nitrogen fertilizer application based on the diagnosis of $\mathrm{N}$ nutrition of rice plants using chlorophyll meter[J]. J. of Zhejiang Agric. Univ., 1999, 25(2):135-138.

5. Tang Y L, Wang RC, Zhang J H et al. Study on determining nitrogenous levels of barley by hyperspectral and chlorophyll Meter [J] . J. of Triticeae Crops, 2003, 23 (1) :63-66. 